\title{
Is being first-born another risk factor for metabolic and cardiovascular diseases?
}
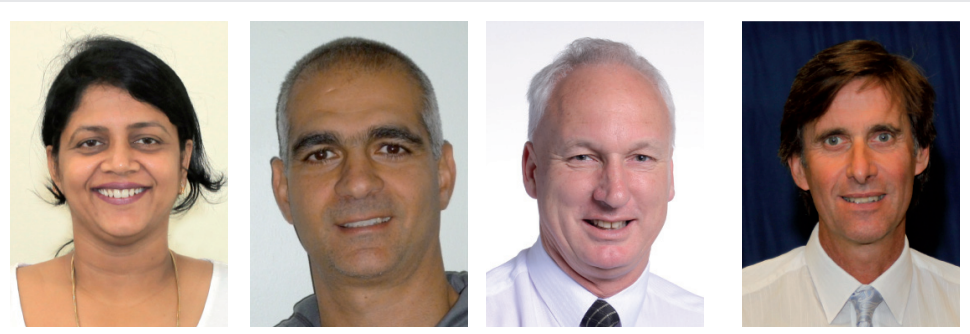

Ahila Ayyavoo ${ }^{1,2}$, José GB Derraik1, Paul L Hofman ${ }^{1,2} \&$ Wayne S Cutfield ${ }^{\star 1,2}$

'Liggins Institute, University of Auckland, Private Bag 92019, Auckland, New Zealand

2Gravida: National Centre for Growth \& Development, Auckland, New Zealand

*Author for correspondence: Tel.: +649923 5118 - Fax: +649373 8763 w w.cutfield@auckland.ac.nz

Birth rates have been steadily declining throughout the world, particularly in Europe and many Asian countries [1]. This reduction in birth rates is a result of a number of factors, including government policies (e.g. one-child policy in mainland China), greater family planning, personal choice and economic constraints [2]. As a result, there has been a large increase in the number of one-child families and, consequently, a considerable increase in the proportion of first-born children within many populations [2].

Thus, any adverse health outcomes that are associated with being first-born (primogeniture) would likely affect an ever-increasing proportion of the world's population. Notably, only recently has evidence emerged on the consequences of primogeniture on long-term metabolic and cardiovascular health risks.

\section{Early life events, birth weight \& later diseases}

Traditionally, the causes of adult cardiovascular diseases have clustered into two broad areas: genetic predisposition and lifestyle. However, in recent years, the impact of early life events has been recognized as a third important domain affecting an individual's disease risk in adulthood.

It is now well established that adverse events early in life are associated with long-term changes that may lead to later metabolic and cardiovascular disease [3]. Low birth weight is an indirect indicator of poor intrauterine milieu and adverse health outcomes have been demonstrated in association with decreasing birth weight, even in offspring born appropriatefor-gestational-age. Studies on survivors of the Dutch famine [4] and research in the UK by Barker [3] have shown that the offspring of mothers exposed to nutritional or physiological stress during pregnancy are at increased risk of metabolic and cardiovascular disease in later life. There is extensive evidence linking a reduction in birth weight with increased risk of insulin resistance, Type 2 diabetes mellitus, hypertension, cardiovascular disease, stroke and cancer [3].

\section{"...first-borns are phenotypically different to later-borns in both childhood and adulthood."}

We have recently observed that, despite similar gestational ages, first-borns were, on average, $250 \mathrm{~g}$ lighter than later-borns at birth [2]. This reduction in birth weight among first-borns had been previously noted $[5,6]$, suggesting that primogeniture may be associated with a degree of nutrient restriction in utero.

Although the underlying causes are still unclear, there is a suggestion that changes in placentation may account for the observed differences in birth weight [7]. Multiparous women who had earlier uncomplicated pregnancies have better trophoblast invasion and placentation compared with women who are pregnant for the first time [8,9]. Beneficial immunomodulating effects are also seen in multiparous pregnancies [8]. These factors could account for improved nutrient flow to later-born fetuses, consequently improving fetal growth in later pregnancies.

Exposure to nutritional or physiological insult at different periods of gestation has been associated with various adverse outcomes in offspring [4]. However, the timing of possible stressors to
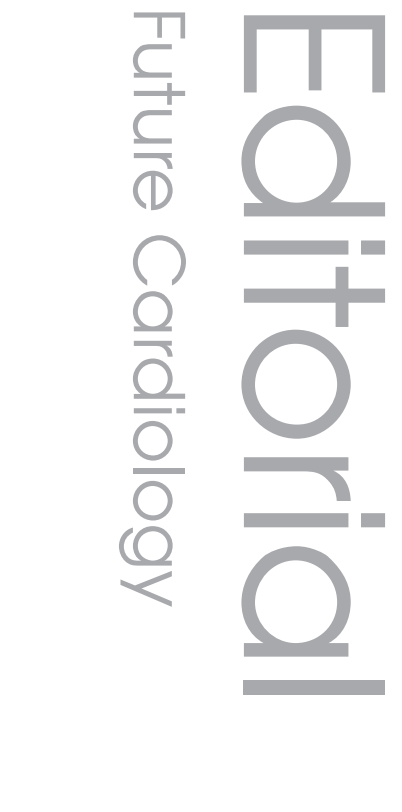

列


first-born fetuses is not known. A stress early in pregnancy does not affect birth weight as much as insults late in the third trimester. Thus, first-borns may be subjected to an adverse in utero environment late in pregnancy, which would explain a reduction in birth weight. Alternatively, it is possible that first-borns may be subjected to a less favorable intrauterine environment throughout the entire pregnancy.

\section{Phenotypic differences \\ \& cardiovascular risk}

Irrespective of the timing and nature of possible stressors in utero, it is clear that first-borns are phenotypically different to later-borns in both childhood and adulthood [2,5,10]. Studies have shown that first-born children were taller (with a progressive reduction in height with subsequent births) and had greater circulating IGF-I concentrations than later-born children $[2,10]$. There was a reduction of $1.3 \mathrm{~cm}$ in height in secondborn children compared with first-borns, with a further $2 \mathrm{~cm}$ decrease from second- to third-born children [10]. Other studies revealed similar difference in height between first- and later-borns [11]. Taller stature in childhood is positively associated with overweight status and obesity later in life [12], and a large study in Brazil of over 2000 men found that first-borns were taller and had greater fat mass than later-borns [13].

There is also mounting evidence that firstborns have an increased risk of adverse health outcomes later in life. Earlier studies have shown that first-borns were more likely to develop Type 1 diabetes mellitus [14], allergic disorders [15] and psychological issues [16]. In a prospective cohort study, primogeniture was a significant risk factor for increased adiposity in young adulthood [17]. Nearly four decades ago, a study in young adults suggested that first-borns were at a greater risk of developing hypertension [18]. An unpublished study presented at an American Heart Association forum 12 years ago by Ferratini and colleagues indicated that primogeniture was associated with an increased rate of heart disease in a population of 358 patients [101]. The previously mentioned Brazilian study also found that, in association with their increased fat mass, first-borns had higher metabolic risk z-scores compared with later-borns [13]. The metabolic risk z-score was calculated as the average of the z-scores of fat mass, lipid profile and blood pressure, with a higher score indicative of a higher risk of the metabolic syndrome [13]. The same research group observed a similar increase in metabolic risk among first-born women [19].
Importantly, we have recently shown that insulin sensitivity (as determined by Bergman's minimal model) was $21 \%$ lower in first-born children compared with later-borns [2]. It is worth noting that neither a reduction in birth weight nor current adiposity explain the observed difference in insulin sensitivity, as both were accounted for in all statistical models [2]. To put the observed reduction in insulin sensitivity in context, the magnitude of the change $(20 \%)$ is similar to the increase seen with medications used to treat diabetes in adults, such as metformin [20].

A reduction in insulin sensitivity (insulin resistance) with compensatory hyperinsulinism is associated with metabolic and cardiovascular diseases. Insulin resistance leads to reduced endothelial cell production of nitric oxide, greater myosin light chain activation with vasoconstriction and reduced skeletal muscle glucose transport [21]. In a cohort of 208 apparently healthy middle-aged nonobese men, insulin resistance was an independent predictor of many disorders 4-11-years later, including Type 2 diabetes mellitus, hypertension, coronary heart disease, stroke and cancer [22]. Facchini et al. showed that $36 \%$ of individuals in the least insulin-sensitive tertile suffered one or more of these adverse events; by contrast, no events were recorded among individuals in the most insulin-sensitive tertile [22].

66...reduction in insulin

sensitivity ... and ... increased blood

pressure seen in first-borns may have

long-term consequences for cardiovascular health."

Furthermore, 24-h ambulatory blood pressure monitoring showed that first-born children also had higher daytime systolic $(+5 \mathrm{mmHg})$ and diastolic $(+4 \mathrm{mmHg})$ blood pressure [2]. This is equivalent to the observed difference in systolic and diastolic pressure between an obese child and a child of normal BMI [23]. Higher blood pressure tracks from childhood into adulthood and the prevalence of hypertension is 3.6-times more common in those with a childhood blood pressure in the highest quintile [24]. In the prospective 1993 Pelotas birth cohort [5], the difference in systolic blood pressure in firstborns was attributed to early catch-up growth and the difference in diastolic blood pressure to reduced physical activity. Nonetheless, the increased blood pressure seen in first-borns may 
have long-term consequences for cardiovascular health.

\section{Future perspective}

There is mounting evidence suggesting that primogeniture is a contributing factor to overall metabolic and cardiovascular disease risks in later life. However, birth order alone does not predict metabolic or cardiovascular disease. The relevance of these findings will likely continue to increase with the worldwide trend towards small nuclear families. Notably, first-borns are the largest identifiable study group (accounting for more than half of the world's population), so that any associated health risks could have enormous public health consequences.

Further research is warranted to address a number of important questions associated with birth order. What is the contribution of primogeniture across ethnicities to the development of diabetes, hypertension, heart disease and other insulin-resistant disorders? Do the adverse changes seen in first-born children persist into adult life? It seems that altered placental nutrient supply to first-born fetuses may influence metabolic programming via mechanisms other than those that lead to a reduction in birth weight. So, what are the triggers and mechanisms underpinning these programmed changes in first-borns? Such data would be valuable to better evaluate the extent of the disease risk among the ever-increasing proportion of primogeniture worldwide.

\section{Financial \& competing interests disclosure}

The authors' research findings referred to in this article were supported by funding from Gravida: National Centre for Growth and Development (New Zealand) and the Australasian Pediatric Endocrine Group. They also acknowledge the Paykel Trust for long-term funding of the Maurice and Agnes Paykel Clinical Research Unit at the Liggins Institute, University of Auckland. The authors have no other relevant affiliations or financial involvement with any organization or entity with a financial interest in or financial conflict with the subject matter or materials discussed in the manuscript apart from those disclosed.

No writing assistance was utilized in the production of this manuscript.

\section{References}

1. Caldwell JC, Schindlmayr T. Explanations of the fertility crisis in modern societies: a search for commonalities. Popul. Stud. 57(3), 241-263 (2003).

2. Ayyavoo A, Savage T, Derraik JGB, Hofman PL, Cutfield WS. First-born children have reduced insulin sensitivity and higher daytime blood pressure compared with later-born children. J. Clin. Endocrinol. Metab. 98(3), 1248-1253 (2013).

3. Barker DJ. Mothers, Babies, and Health in Later Life. Elsevier Health Sciences, Amsterdam, The Netherlands (1998).

4. Roseboom T, De Rooij S, Painter R. The Dutch famine and its long-term consequences for adult health. Early Hum. Dev. 82(8), 485-491 (2006).

5. Wells JC, Hallal PC, Reichert FF, Dumith SC, Menezes AM, Victora CG. Associations of birth order with early growth and adolescent height, body composition, and blood pressure: prospective birth cohort from Brazil. Am. J. Epidemiol. 174(9), 1028-1035 (2011).

6. Cote K, Blanchard R, Lalumière ML. The influence of birth order on birth weight: does the sex of preceding siblings matter? J. Biosoc. Sci. 35(3), 455-462 (2003).

7. Oken E, Kleinman K, Rich-Edwards J, Gillman M. A nearly continuous measure of birth weight for gestational age using a
United States national reference. $B M C$ Pediatr. 3(1), 6 (2003).

8. Litwin S, Cortina ME, Barrientos GL, Prados MB, Roux ME, Miranda SE. Multiparity increases trophoblast invasion and vascular endothelial growth factor expression at the maternal-fetal interface in mice. J. Reprod. Immunol. 85(2), 161-167 (2010).

9. Khong TY, Adema ED, Erwich JJ. On an anatomical basis for the increase in birth weight in second and subsequent born children. Placenta 24(4), 348-353 (2003).

10. Savage T, Derraik JGB, Miles HL, Mouat F, Cutfield WS, Hofman PL. Birth order progressively affects childhood height. Clin. Endocrinol. doi:10.1111/cen.12156 (2013) (Epub ahead of print).

11. Ghosh JR, Bandyopadhyay AR. Income, birth order, siblings, and anthropometry. Hum. Biol. 78(6), 733-741 (2006).

12. Bosy-Westphal A, Plachta-Danielzik S, Dorhofer RP, Muller MJ. Short stature and obesity: positive association in adults but inverse association in children and adolescents. Br. J. Nutr. 102(3), 453-461 (2009).

13. Siervo M, Horta BL, Stephan BC, Victora CG, Wells JC. First-borns carry a higher metabolic risk in early adulthood: evidence from a prospective cohort study. PLoS ONE 5(11), e13907 (2010).
14. Bingley PJ, Douek IF, Rogers CA, Gale EA. Influence of maternal age at delivery and birth order on risk of Type 1 diabetes in childhood: prospective population based family study. BMJ 321(7258), 420-424 (2000).

15. Karmaus W, Arshad H, Mattes J. Does the sibling effect have its origin in utero? Investigating birth order, cord blood immunoglobulin E concentration, and allergic sensitization at age 4 years. Am. J. Epidemiol. 154(10), 909-915 (2001).

16. Elliott BA. Birth order and health: major issues. Soc. Sci. Med. 35(4), 443-452 (1992).

17. Stettler N, Kumanyika SK, Katz SH, Zemel BS, Stallings VA. Rapid weight gain during infancy and obesity in young adulthood in a cohort of African Americans. Am. J. Clin. Nutr. 77(6), 1374-1378 (2003).

18. Paffenbarger RS, Thorne MC, Wing AL. Chronic disease in former college students. VIII. Characteristics in youth predisposing to hypertension in later years. $\mathrm{Am}$. J. Epidemiol. 88(1), 25-32 (1968).

19. Siervo M, Stephan BC, Colantuoni A, Wells JC. First-borns have a higher metabolic rate and carry a higher metabolic risk in young women attending a weight loss clinic. Eat. Weight Disord. 16(3), e171-e176 (2011). 


\section{Editorial Ayyavoo, Derraik, Hofman \& Cutfield}

20. Ceriello A, Johns D, Widel M, Eckland DJ, Gilmore KJ, Tan MH. Comparison of effect of pioglitazone with metformin or sulfonylurea (monotherapy and combination therapy) on postload glycemia and composite insulin sensitivity index during an oral glucose tolerance test in patients with Type 2 diabetes. Diabetes Care 28(2), 266-272 (2005).

21. Sowers JR. Insulin resistance and hypertension. Am. J. Physiol. Heart Circ. Physiol. 286(5), H1597-H1602 (2004).
22. Facchini FS, Hua N, Abbasi F, Reaven GM. Insulin resistance as a predictor of age-related diseases. J. Clin. Endocrinol. Metab. 86(8), 3574-3578 (2001).

23. He Q, Ding ZY, Fong DY, Karlberg J. Blood pressure is associated with body mass index in both normal and obese children. Hypertension 36(2), 165-170 (2000).

24. Bao W, Threefoot SA, Srinivasan SR, Berenson GS. Essential hypertension predicted by tracking of elevated blood pressure from childhood to adulthood: the Bogalusa Heart Study. Am. J. Hypertens. 8(7), 657-665 (1995).

\section{Website}

101. Young E. Firstborn people prone to heart disease. New Scientist (2001). www.newscientist.com/article/dn2204firstborn-people-prone-to-heart-disease.html 